\title{
LA DESIGNACIÓN DE FUNCIONARIOS EN COMISIÓN POR EL PODER EJeCUTIVO
}

\section{Pablo Luis Manili}

Universidad de Buenos Aires

pablo.manili@gmail.com

\section{Introducción}

El artículo 99, inciso 19 de la Constitución Nacional (CN) establece que el presidente "puede llenar las vacantes de los empleos que requieren acuerdo del Senado y que ocurran durante su receso por medio de nombramientos en comisión que expirarán al fin de la próxima legislatura”. Este inciso fue modificado en 1860, agregándose la parte referida a la expiración de esos nombramientos, que antes no existía. En la Constitución de 1853 era el artículo 83, inciso 23, y entre 1860 y 1994 fue el 86, inciso 22.

La norma fue incluida bajo la inspiración de la Constitución de los Estados Unidos, cuyo artículo II, Sección 2, párrafo 3 reza: "El Presidente tendrá el derecho de cubrir todas las vacantes que ocurran durante el receso del Senado, extendiendo nombramientos provisionales que terminarán al final del siguiente período de sesiones". La palabra "nombramientos" también puede ser traducida como "comisiones" y de allí se tomó el término "nombramientos en comisión", que debe ser interpretado como un nombramiento interino, provisorio, hasta tanto el Senado preste o no el acuerdo, o pase el tiempo con el que cuenta para prestarlo. Interpretando esta norma, Hamilton, en El Federalista No 67, sostenía que:

La competencia ordinaria de designación está conferida al Presidente y al Senado conjuntamente por lo tanto sólo puede ser ejercida mientras el Senado esté en sesiones; pero sería impropio obligar a este cuerpo a estar permanentemente en sesión para la designación de funcionarios, como las vacantes pueden producirse durante el receso puede ser necesario para el servicio público cubrirlas sin dilación. 
Haciendo uso de esta atribución, el presidente Eisenhower, después de la Segunda Guerra Mundial, designó en comisión al presidente de la Corte Earl Warren en 1953 y a los ministros William Brennan, en 1956, y Poter Stewart, en 1958, durante recesos del Congreso (Sola Juan, 2015).

La norma de la Constitución nacional parece de sencilla interpretación a primera vista, pero tiene sus dificultades y ha generado debates doctrinarios. Nuestro análisis de ella es el que se describe a continuación.

\section{Interpretación restrictiva}

Entendemos que la interpretación de esta atribución presidencial debe ser muy restrictiva por los siguientes motivos:

a) En primer lugar, porque - por el principio de especificidad- las normas que establecen facultades en cabeza de los poderes del Estado deben ser interpretadas en forma estricta, a diferencia de las normas constitucionales que consagran derechos para las personas, que deben serlo en forma extensiva.

b) En segundo lugar, porque es una norma facultativa, dado que el inciso bajo estudio no obliga al presidente a hacerlo ni le marca un programa o proyecto como hacen otras normas, sino que tan solo lo faculta para cubrir vacantes en los cargos que requieran de urgente cobertura. Si no quiere hacerlo y prefiere esperar a que concluya el receso del Senado, es válido y consideramos que es más republicano.

c) A ello se le agrega que se trata de una norma excepcional, porque prevé un mecanismo de emergencia para cubrir vacantes que no admiten demora. Nótese que cuando el presidente ejerce esta atribución altera el orden lógico de las cosas y genera un hecho consumado que violenta la voluntad, tanto de los funcionarios así nombrados (especialmente si son jueces) como de los senadores que deben considerar sus pliegos. El funcionario designado asume y ejerce el cargo sin tener acuerdo del Senado, cuando normalmente ocurre lo contrario. Ello genera que, en estos casos, el Senado deba considerar y evaluar pliegos de personas que están en ejercicio del cargo y, si son jueces, podría darse el caso de que esos jueces estén conociendo en causas en las que están interesados los senadores, o incluso el presidente, y ello privará de independencia al juez (para tramitar la causa) y a los senadores (para evaluar su pliego). En ese entorno, esos jueces podrían sentirse compelidos a fallar de modo tal que agrade (o que al menos no moleste) a las bancadas que forman la mayoría del Senado para obtener ese acuerdo, y ello claramente afecta su independencia. La estabilidad en el cargo es la mayor garantía 
para la independencia de criterio de quienes tienen en sus manos decidir sobre el honor, la libertad y la fortuna de todos los argentinos.

En síntesis, se trata de una facultad que debe ser ejercida con la máxima prudencia por parte del presidente, solo en casos de extrema necesidad de cubrir cargos que requieran el acuerdo del Senado. Por todo ello, debe ser interpretada de manera muy restrictiva.

\section{3. ¿A qué empleos se refiere?}

A todos los que requieran acuerdo del Senado, dado que la norma no hace distinción entre algunos u otros, por lo cual no hay que distinguir (ubi lex non distinguit nec nos distinguere debemus). Cabe aclarar que la palabra "empleo" es utilizada en la Constitución en muchos casos, aludiendo a distintos tipos de funcionarios, integrantes de los tres poderes del Estado. Por ejemplo: en el artículo 16, al referirse a la idoneidad como único requisito para el acceso a cargos públicos; en el artículo 34, cuando prohíbe a los jueces federales serlo de provincia simultáneamente; en el artículo 36, cuando alude a la inhabilitación para quienes cometan delitos dolosos contra la administración pública; en el artículo 60, referido a los funcionarios destituidos por juicio político; en el artículo 75, inciso 20, al referirse a los tribunales inferiores y empleos judiciales que puede crear el Congreso, etc. Por ello, tampoco cabe hacer distingos a partir de la utilización de ese vocablo y debemos interpretar que se refiere a todo empleo público, de cualquier jerarquía, cuyo nombramiento esté dentro de la competencia del presidente con acuerdo del Senado. Ello implica que se refiere a los siguientes nombramientos, previstos en el artículo 99 de la $\mathrm{CN}$ :

a) Embajadores, ministros plenipotenciarios, encargados de negocios y agentes consulares (inciso 7).

b) Oficiales superiores de las Fuerzas Armadas (inciso 13).

c) El caso de los jueces de la Corte Suprema (inciso 4) requiere cierto análisis por la vigencia del Decreto 222/2003, que regula el procedimiento de selección de jueces y establece ciertas etapas cuyo cumplimiento debe ser previo a la elevación del pliego al Senado (y no solo previo al tratamiento por el Senado). La norma establece lo siguiente:

- Producida una vacante, en un plazo máximo de treinta días se publicará en el Boletín Oficial y en por lo menos dos diarios de circulación nacional, durante tres días, el nombre y los antecedentes curriculares de los candidatos a cubrir la vacante. 
- Esos candidatos deberán presentar una declaración jurada con la nómina de todos los bienes propios y de su grupo familiar (en los términos del artículo 6 de la Ley 25188 de Ética de la Función Pública). Deberán informar las asociaciones civiles y sociedades comerciales que integren o hayan integrado, los estudios de abogados a los que pertenecieron o pertenecen, la nómina de clientes o contratistas y, en general, cualquier tipo de compromiso que pueda afectar la imparcialidad de su criterio por actividades propias o de sus familiares directos, con la finalidad de "permitir la evaluación objetiva de la existencia de incompatibilidades o conflictos de intereses".

- Los ciudadanos en general, las organizaciones no gubernamentales, los colegios y asociaciones profesionales, las entidades académicas y de derechos humanos podrán en el plazo de quince días a contar desde la última publicación en el Boletín Oficial presentar por escrito y de modo fundado y documentado las posturas, observaciones y circunstancias que consideren de interés expresar respecto a los incluidos en el proceso de preselección, con declaración jurada respecto a su propia objetividad sobre los propuestos.

- Se recabará de la Administración Federal de Ingresos Públicos, preservando el secreto fiscal, un informe relativo a la situación patrimonial y al cumplimiento de las obligaciones impositivas y previsionales de las personas eventualmente propuestas.

Luego de cumplido ese proceso, el artículo 9 del decreto establece que

En un plazo que no deberá superar los quince días a contar desde el vencimiento del establecido para la presentación de las posturas u observaciones, haciendo mérito de las razones que abonaron la decisión tomada, el Poder Ejecutivo Nacional dispondrá sobre la elevación o no de la propuesta respectiva".

Frente a ello, debemos dilucidar si la designación en comisión puede tener efecto y el funcionario puede asumir el cargo, en comisión, antes de cumplido ese proceso o si este es previo a la asunción del cargo en comisión. En otras palabras, ¿la designación en comisión solo posterga el acuerdo del Senado o dilata también los pasos establecidos por el decreto? Entendemos que solo retrasa el acuerdo del Senado y que no puede soslayarse el cumplimiento de los pasos establecidos por el Decreto 222/2003 por los siguientes motivos:

- Porque lo único que habilita a realizar designaciones en comisión, según la

Énfasis agregado. 
Constitución, es la circunstancia de que el Senado esté en receso y, por lo tanto, no pueda considerar el pliego, pero nada impide que se lleve a cabo el trámite del Decreto 222/2003 en forma previa a la elevación de la propuesta

- Porque ese decreto regula ciertos requisitos que deben estar cumplidos antes de que el presidente eleve la propuesta al Senado, ya que se trata de indagaciones que formarán la base de la decisión que adopte el presidente de proponer a ese candidato y no solo como fundamento de la evaluación que hace el Senado. Así surge del artículo 9 del decreto.

- Por el principio de inderogabilidad de los reglamentos generales mediante actos administrativos particulares: si el Poder Ejecutivo autolimitó su voluntad en la designación de jueces de la Corte estableciendo ciertos pasos previos al envío de pliegos al Senado, no puede dejar de lado esa norma para un caso puntual y eludir esos requisitos enviando un pliego en el que no se cumplieron esos pasos.

- Porque de lo contrario se generaría la posibilidad de que asuma el cargo una persona con deudas con la AFIP, evasiones o fraudes impositivos, sanciones de los colegios de abogados, oposiciones fundadas de la sociedad civil, conflictos de intereses, etcétera.

- Porque la atribución de nombrar funcionarios en comisión debe ser interpretada restrictivamente.

- Porque la Corte puede funcionar con los jueces subrogantes, que son los presidentes de las cámaras federales de apelaciones (y eso es lo que ocurre cada vez que hay excusaciones o recusaciones de los jueces titulares).

d) El caso de los jueces inferiores de la nación (inciso 4) también requiere una precisión: solo podría el presidente nombrarlos en comisión si ya existe una terna confeccionada por el Consejo de la Magistratura de la nación, dado que esa terna es "vinculante" (artículos 99, inciso 4, y 114 de la CN).

e) Para los demás nombramientos que hace el presidente y que no requieren acuerdo del Senado, la norma no aplica, por ejemplo, para el jefe de gabinete y los demás ministros del despacho, los oficiales de su secretaría y los empleados cuyo nombramiento no está reglado de otra forma por la Constitución (inciso 7). Ello así porque, al no requerir acuerdo del Senado, carece de sentido nombrarlos en comisión, pudiendo hacer nombramientos definitivos. 


\section{4. ¿A qué vacantes se refiere?}

Es necesario dilucidar en primer lugar la cuestión temporal, es decir, si la norma se refiere a las vacantes producidas durante el receso en el cual el presidente realiza el nombramiento o si, además, puede cubrir vacantes que se hubieran generado durante el período ordinario de sesiones del Congreso o en un receso anterior de ese órgano. Bidart Campos (2002/2004, pp. 333 y ss.), De Vedia (1907, p. 476) y Ekmekdjian (2016, p. 132) sostienen que se pueden llenar vacantes producidas con anterioridad al receso.

Discrepamos de esa postura categóricamente por varias razones: (i) en primer lugar, porque la norma reza "que ocurran durante su receso", por lo cual solo se podrán llenar las que ocurran durante el receso en el cual son nombrados; no así las ocurridas en anteriores recesos ni las ocurridas durante el período de sesiones previo; (ii) además de esa razón literal, hay que tener en cuenta que es una facultad excepcional que se le concede al presidente y, por lo tanto, su interpretación debe ser restrictiva, como expresamos más arriba; y (iii) la postura de la que discrepamos se presta a abusos: una vez producida la vacante, el presidente podría dejar pasar todo lo que resta del período de sesiones (si la vacante se produjo estando reunido el Congreso); o bien dejar pasar todo un período de sesiones (si la vacante se produjo en el receso anterior) y esperar al receso para proponer a funcionarios que asumirán el cargo en comisión y con ello presionar políticamente al Senado para que apruebe su pliego mientras ellos están en ejercicio del cargo.

La postura según la cual se pueden cubrir por este mecanismo vacantes que se hubieran producido antes del receso tiene origen en algunas opiniones doctrinarias de autores norteamericanos ${ }^{2}$ y en un informe preparado por el senador Joaquín V. González para el Senado en 1917 con motivo de unas designaciones que había hecho el presidente en la Comisión Municipal (porque no existía, desde 1915, el Concejo Deliberante) de la ciudad de Buenos Aires (por entonces dependiente del Poder Ejecutivo). Ese informe motivó una reforma del reglamento del Senado, en la cual se incorporó una norma interpretativa de la Constitución según la cual la frase "que ocurran" debía leerse como "que existan" durante el receso. Pero entendemos que ese precedente no resulta aplicable en la actualidad por cuatro motivos: (i) porque no se refería a cargos federales, sino a cargos locales de la municipalidad, para los cuales la Constitución no exigía acuerdo del Senado; (ii) porque esas normas del reglamento fueron

2 Ver las citas de Putney y Watson en González Calderón (1916, p. 372). 
derogadas; (iii) porque las atribuciones que el presidente tenía en la ciudad capital también fueron derogadas al reconocerse su autonomía en la reforma de 1994; (iv) porque, aun cuando todo ello estuviera vigente, ni el informe de un senador (por prestigioso que sea como constitucionalista) ni el reglamento de una cámara tienen autoridad alguna para cambiar lo que la Constitución expresamente establece. La frase "que ocurran" significa "que ocurran" y no que hubieran ocurrido con anterioridad y que "aún subsistan", como se pretende. Además, el espíritu de la Constitución también apunta en otro sentido, como expresamos más arriba. En síntesis, si el presidente no hace uso de esta facultad durante el mismo receso en el cual se produjo la vacante, ya no podrá hacer designaciones en comisión para esos cargos.

Es de destacar que tanto González Calderón (1916, p. 372) como Linares Quintana (1987, p. 699) mencionan el informe de Joaquín V. González, pero no adhieren a esa postura, sino que guardan silencio respecto a sus opiniones personales: simplemente lo citan.

\section{5. ¿Qué significa la frase "que expirarán al fin de la próxima legislatura"?}

Entendemos que si los funcionarios en comisión no son ratificados durante el período de sesiones ordinarias que comienza el 1 de marzo y finaliza el 30 de noviembre, caducan sus cargos. Sin embargo, la Corte -en el caso Lastra de 1946- sostuvo: "Terminadas las sesiones de prórroga del Congreso cesan en sus funciones los jueces nombrados en comisión [...] a quien el Senado no hubiese prestado el acuerdo correspondiente". ${ }^{3}$ Es decir que extendió el plazo a las sesiones de prórroga de las ordinarias, criterio demasiado amplio que no se compadece con la excepcionalidad con la que hay que interpretar este instituto.

\section{6. ¿Qué otros modos de caducidad de mandatos en comisión existen?}

En el caso Montero ${ }^{4}$ de 1958 la Corte sostuvo que: "El funcionario designado en comisión cesa si el Senado rechaza su acuerdo, aun antes de expirar el período de sesiones. El inc. 22 no ha tenido por finalidad asegurar al funcionario nombrado una inamovilidad irrevocable durante todo el período legislativo".

También agregó que "quedan efectivamente revocados cuando el Senado

3 Fallos: 206:130.

4 Fallos: 241:151. 
presta acuerdo a la misma o distinta persona, a propuesta del Poder Ejecutivo". Esta afirmación de la Corte presupone una desprolijidad del presidente, porque para que el Senado pueda prestar acuerdo a otra persona, el presidente tiene que haber enviado su pliego, contradiciéndose así con el nombramiento en comisión (y el consiguiente envío del pliego del funcionario nombrado interinamente). Bidart Campos (1967, pp. 116-117) también se refirió a esa posibilidad y sostuvo que el presidente no podía retirar el nombramiento hecho en comisión, pero que si proponía a otro candidato, el Senado podría rechazarlo. Entendemos que el presidente no solo no puede retirar el nombramiento en comisión, sino que tampoco puede enviar un pliego distinto para el mismo cargo, dado que ello implicaría un desistimiento tácito de la primera designación.

Es decir que la caducidad del nombramiento en comisión se produce por cuatro causales:

a) Aprobación del pliego del funcionario interino.

b) Rechazo expreso del pliego del funcionario nombrado en comisión; coincidimos con González Calderón (1916, p. 371) en cuanto a que, rechazado en forma expresa el pliego, el funcionario en comisión cesa su mandato ese mismo día.

c) Vencimiento del período de sesiones ordinarias (y las de prórroga también, según la citada jurisprudencia de la Corte, de la que discrepamos) sin que se hubiera aprobado el pliego.

d) Aprobación del pliego de otra persona para el mismo cargo.

\section{7. ¿Puede invocarse esta atribución para cubrir cargos nuevos?}

Bidart Campos (2002/2004, p. 334) plantea esta pregunta y responde que también pueden ser llenados en comisión ese tipo de cargos. Pero entendemos que es necesario hacer ciertas precisiones al respecto: supongamos el caso de una ley que amplía la cantidad de miembros de la Corte Suprema o que crea nuevos juzgados y es sancionada durante los últimos días de las sesiones del Congreso, sean ordinarias, o de prórroga o extraordinarias, y la ley queda promulgada después de finalizadas estas.

En primer lugar, consideramos que, en esos casos, para evitar problemas, la ley que crea el cargo debería establecer su entrada en vigencia a partir del 30 de marzo (como mínimo), para darle al menos 30 días de tiempo al Senado para que considere el pliego en las sesiones ordinarias que comienzan el primer día de ese mes y que, de ese modo, la designación sea efectuada de acuerdo al modo ordinario que manda la Constitución y que el presidente no se vea tentado a 
llenar el cargo utilizando esta vía excepcional. Pero si la ley no previera ese período de vacatio legis, entendemos que la vacante podría ser llenada en comisión por el presidente durante el receso en el cual entró en vigor esa ley

También es preciso aclarar que:

a) Si se trata de cargos nuevos de jueces de la Corte creados durante el receso del Senado, es necesario cumplir antes con el Decreto 222/2003, como analizamos más arriba.

b) Si se trata de cargos nuevos de jueces inferiores generados durante el receso, es prácticamente imposible que pueda darse el caso de que el presidente haga un nombramiento en comisión porque, luego de creado el cargo, el Consejo de la Magistratura debe convocar a concurso, examinar a los candidatos, resolver las (frecuentes) impugnaciones y elevar la terna vinculante al Ejecutivo. Y es harto difícil que ello ocurra durante el breve período en el que el Senado está en receso (del 1 de diciembre al 28 de febrero, salvo que haya sesiones de prórroga o extraordinarias, en cuyo caso es más breve). Como expresamos más arriba, si no hay terna para jueces inferiores, no puede haber nombramiento en comisión, porque de lo único que la Constitución releva al presidente (transitoriamente) en estos acasos es del acuerdo del Senado, pero no de la existencia de una terna vinculante de candidatos

Hay otra pregunta que cabe formular aquí y que solo se ha ocupado de ella Agustín de Vedia (1907) hace más de un siglo: ¿qué pasa si es el presidente el que genera la vacante durante el receso para aprovecharse de esa situación y hacer un nombramiento en comisión? Sostenía este autor:

Las vacantes que ocurran, dice la Constitución. Se entiende que esa expresión designa las vacantes que provienen de una causa fortuita, como muerte, renuncia ausencia, etc.; no las que nacen de la voluntad, un designio o intención previa. El presidente no podría provocar una vacante y decir luego que esa vacante ha ocurrido. No puede hacer el vacío con el objeto de llenarlo. (p. 476)

Coincidimos con esa afirmación y aclaramos que obviamente ello aplica solo a los funcionarios que el presidente puede desplazar por sí, sin necesidad de juicio político, es decir que no aplica a los jueces de ninguna instancia. 


\section{8. ¿Puede el presidente volver a proponer al funcionario rechazado por el Senado?}

Resta, por último, responder esta pregunta. Entendemos, con González Calderón (1916, p. 374), que no puede hacerlo. Es decir, el funcionario nombrado en comisión y rechazado por el Senado no puede ser vuelto a proponer para el mismo cargo en forma definitiva.

\section{9. ¿Puede el presidente revocar la designación?}

Entendemos que, una vez efectuada, el presidente no puede revocarla, sino que queda a consideración del Senado otorgar o no el acuerdo, como adelantamos más arriba. Ello es así porque la posición de esos funcionarios sería muy endeble y carecerían de estabilidad (y, por lo tanto, de independencia en el caso de los jueces) durante el período que medie entre la designación en comisión y el acuerdo o rechazo del Senado.

Incluso, coincidimos con Bidart Campos (2002/2004, p. 335) en que si el presidente no la enviara al Senado, este podría avocarse a su conocimiento solicitando el pliego al presidente. El autor citado agrega que el presidente no puede dejar de enviar el pliego durante el siguiente período de sesiones del Senado, porque ello le permitiría la siguiente argucia: dejar pasar todo ese período y, una vez finalizado, volver a nombrar en comisión a ese funcionario y así sucesivamente.

\section{0. ¿Qué tipo de instrumento debe firmar el presidente?}

Cabe aclarar también que para hacer esa designación el presidente emite un decreto autónomo en el marco de los incisos 1, 4 (si son jueces), 7 (si son diplomáticos), 13 (si son militares) y 19 del artículo 99 de la CN, no siendo necesario dictar un decreto de necesidad y urgencia. Ello así porque si bien está ejerciendo una atribución de urgencia, el contenido no es de carácter legislativo.

\section{Utilización de esta atribución}

a) Algunos ministros de la Corte fueron nombrados en comisión y luego recibieron el acuerdo del Senado entre fines del siglo XIX y comienzos del XX (Diegues, 2015): (i) en 1889, el presidente Miguel A. Juárez Celman nombró al Dr. Luis V. Varela en la Corte el 03/04/1889, obteniendo el acuerdo del Senado recién en junio de ese año; (ii) Abel Bazán, nombrado en comisión 
por el mismo presidente el 13/01/1890, obtuvo el acuerdo el 23 de junio de ese año; (iii) el Dr. Benjamín Paz fue nombrado en comisión por el presidente Carlos Pellegrini el 29/03/1892; y (iv) el Dr. Dámaso Palacio fue designado en comisión por José Figueroa Acorta el 21/03/1910. Luego de ello, esa cláusula cayó en desuso durante varias décadas en lo atinente a la designación de jueces de la Corte Suprema.

b) El presidente interino José M. Guido, por Decreto 9753 del 17 de septiembre de 1962, nombró en comisión como juez de la Corte a José F. Bidau, en momentos en que el Congreso estaba "en receso" por el golpe de estado ocurrido meses antes y por decisión del propio Guido. Luego de reiniciadas las sesiones del Senado, como este no prestó acuerdo a dicho juez, una vez vencido el período ordinario de sesiones el 30 de septiembre de 1964, renunció el 1 de octubre de ese año.

Como se advierte, los antecedentes reseñados hasta aquí no prestan mayor utilidad porque no provienen de gobiernos democráticos, dado que los mencionados en "a)" ocurrieron durante períodos signados por el fraude electoral y el recién estudiado aconteció durante un gobierno de facto, que solo tenía la fachada de un presidente interino que había jurado ante la Corte Suprema al asumir el cargo y con el Congreso disuelto.

c) En 1990, el presidente Carlos Menem nombró a siete jueces penales en comisión invocando el entonces artículo 86, inciso 22 de la CN (actual 99, inciso 19). La cámara de apelaciones tomó juramento solo a dos, elevando el caso de los otros cinco "en consulta” a la Corte Suprema, muy poco después de su ampliación y de la conformación de la "mayoría automática" que durante toda esa década convalidó la enorme mayoría de las medidas adoptadas por el gobierno. ${ }^{5}$ En un extraño fallo caratulado Asunción de Funciones. Jueces en comisión, ${ }^{6}$ el tribunal encontró que era competente para expedirse sobre el tema pese a que no había causa judicial, sino una mera consulta. Invocó facultades de superintendencia, pero tampoco dictó una acordada (como suele hacer para cuestiones de superintendencia del Poder Judicial). Lo cierto es que convalidó lo actuado por el presidente con argumentos que consideramos falaces:

- "Cuando la norma de que se trate -en el caso, el art. 86, inc. 22 de la Constitución Nacional- ofrece 'un amplio marco de decisión' es preciso que los

5 Puede verse un análisis de ese período de la Corte en Manili (2017, pp. 253 y ss.).

6 Fallos: 313:1232. 
jueces no se atengan a sus propios 'valores personales' sino que ponderen 'los que apoyan la doctrina y jurisprudencia de su época”. Un sofisma sin mayor explicación.

- "Para interpretar el art. 86 de la Constitución Nacional, lo que importa no es el momento en que la vacante sucede sino el momento en que el Presidente debe actuar". Es decir que, según este "fallo", el presidente puede elegir esperar años para cubrir una vacante y hacerlo cuando más le convenga -por ejemplo, durante el receso del Senado- para nombrarlos en comisión y para que conozcan alguna causa en la que el presidente pudiera estar interesado, sin contar con el acuerdo del Senado.

- "No es recomendable, para la exégesis de las normas jurídicas, el método que se atiene estrictamente a las palabras, ya que lo que debe indagarse, en procura de una aplicación racional, es el espíritu que las informa”. Como es sabido, el primer método de interpretación de las normas es el literal y la propia Corte había dicho reiteradas veces que solo en caso de oscuridad de las normas podía recurrir a otros métodos.

- "En materia jurídica ha de haber siempre una salida que lleve al resguardo del bien común, es así como los jueces tienen el deber de ponderar las consecuencias sociales de su decisión”. El supuesto bien común en este caso era satisfacer los deseos del presidente.

- "La aceptación de soluciones disvaliosas es incompatible con la misión de los jueces y, en tal sentido, entender que lo que el inc. 22 del art. 86 de la Constitución Nacional dice, por ejemplo, es que si la vacante ocurrió el 15 de septiembre y no el $1^{\circ}$ de octubre, el inc. no rige y la vacancia debe prolongarse durante un considerable espacio de tiempo, con serio deterioro de la función o servicio de que se trate, sería 'como volver a la ley (lato sensu) contra sí misma”". Recordemos que hasta la reforma de 1994 el período ordinario de sesiones finalizaba el 30 de septiembre, por eso el tribunal utiliza esos ejemplos. La respuesta obvia a lo expresado por la Corte es que ello es justamente lo que la Constitución manda: si la vacante ocurre durante el período ordinario de sesiones o durante un receso anterior, la cláusula no rige, porque solo se la incluyó para salvar las urgencias que se presenten durante el receso en el cual el presidente hace el nombramiento. Si la vacante se produce dentro del período de sesiones ordinarias, el presidente puede perfectamente enviar un pliego al Senado a los pocos días de ocurrida la vacante (salvo en el caso de los jueces inferiores, ya que antes debe expedirse el Consejo de la Magistratura). El deterioro que pueda producirse por la 
demora en el llenado de la vacante es menor que el que podría generarse si se le permite al presidente acomodar los tiempos a su antojo y utilizar esta atribución excepcional, pensada para cubrir de urgencia los cargos que no admiten demora, de modo de cubrir cualquier vacante. Incluso, en el caso de los jueces, sus cargos son cubiertos por subrogantes, por lo que el servicio de justicia no se ve lesionado.

- La disidencia del Dr. Augusto C. Belluscio, a la cual adherimos, sostuvo: "Las designaciones de jueces en comisión efectuadas por el Poder Ejecutivo Nacional, mediante las cuales se cubrieron cargos que quedaron vacantes en pleno período de sesiones ordinarias del Congreso, no se ajustan a lo dispuesto por el art. 86 inciso $22[\ldots] "$.

d) En el año 2015 se dio otro caso práctico de aplicación de este inciso, cuando el presidente Mauricio Macri sancionó el Decreto 83/2015 a los cuatro días de asumir su mandato (el 14 de diciembre de ese año), designando a dos ministros de la Corte Suprema sin acuerdo del Senado, invocando esta norma. Los motivos expresados para adoptar semejante medida fueron principalmente los siguientes:

- Por las renuncias de los Dres. Eugenio Raúl Zaffaroni y Carlos Fayt existían dos vacantes a cubrir en dicho Tribunal. Lo que esconde el decreto es que la primera de ellas tenía aproximadamente un año de antigüedad (ya que se produjo en diciembre de 2014), es decir que había transcurrido casi todo el receso, que concluyó el 1 de marzo de 2015, y todo el período de sesiones ordinarias de 2015. No se trataba, pues, de una vacante "ocurrida" en ese receso, sino en uno anterior.

- Que la Corte Suprema había quedado integrada por tres jueces, lo que, a criterio del presidente, dificultaba el desenvolvimiento de sus funciones. En realidad, hacía apenas 3 días que se había efectivizado la renuncia del Dr. Fayt (11 de diciembre) y nada exhibía la dificultad aludida. Además, quince días después de ese decreto (es decir, el 31 de diciembre) comenzaría la feria judicial que duraría todo el mes de enero y el período de sesiones ordinarias comenzaría el 1 de marzo del año siguiente, por lo cual las vacantes perdurarían solamente 45 días, de los cuales eran hábiles aproximadamente 32 . La Corte podía funcionar perfectamente durante ese período con tres jueces titulares y dos subrogantes.

- El decreto citó en su apoyo la "Acordada" (así le denominó al fallo analizado más arriba) de la Corte del año 1990, en la cual el tribunal sostuvo que "la 
facultad presidencial de realizar por sí nombramientos en comisión existe tanto respecto de vacantes producidas durante el receso legislativo como respecto de vacantes que ya existan al momento del receso" 7 y algunas opiniones doctrinarias en el mismo sentido, que hemos mencionado más arriba y discrepado de ellas.

- Se citó un supuesto precedente de 1984, en que el presidente Raúl Alfonsín había designado en comisión a los miembros de ciertas Cámaras Federales de Apelación y a tres jueces federales. Pero el precedente no aplicaba al caso porque: (i) ello había ocurrido respecto a jueces inferiores y no a ministros de la Corte Suprema; (ii) en 1983, el Gobierno asumió después de una dictadura militar que, al retirarse, dejó decenas de vacantes en cargos de todo tipo, incluidos los judiciales; (iii) era imprescindible reconstruir democráticamente los tres poderes de gobierno y poner en funcionamiento a esos órganos judiciales, que no estaban funcionando (mientras que la Corte, en 2015, sí lo estaba haciendo); (iv) una decisión aislada de un solo presidente en toda la historia argentina, adoptada en situaciones fácticas totalmente distintas y excepcionales, no genera por sí sola una costumbre constitucional ni un precedente que deba ser seguido o que pueda modificar el texto de la carta magna; y (v) esa decisión fue adoptada antes de la reforma constitucional de 1994, que modificó el mecanismo de designación de jueces de la Corte, agravando la mayoría necesaria y estableciendo la publicidad de la sesión, como ya se explicó.

Además, no se cumplieron en este caso las etapas que prevé el Decreto 222/2003, analizadas más arriba, sino que se las relegó para después de la asunción del cargo, en comisión, de esos dos ministros, y serían cumplidas luego, respecto a dos personas que ya estaban en funciones, lo cual contradice claramente el espíritu de esa norma.

Fueron tantas las críticas a este decreto, tanto de la doctrina como de la sociedad civil, que el presidente dio marcha atrás con su decisión y recién envió los pliegos de esos jueces de la Corte cuando se inició el período ordinario de sesiones del año siguiente y asumieron a mediados de 2016.

$7 \quad$ Fallos: $313: 1232$, considerandos $4^{\circ}$ y $6^{\circ}$. 


\section{Conclusión}

La designación de funcionarios en comisión es una atribución presidencial excepcional y, como tal, de interpretación restrictiva. No puede ser utilizada para cubrir vacantes que no ocurran durante el receso, tampoco para las que se hayan producido en recesos anteriores o durante el período de sesiones del Congreso.

\section{Bibliografía}

Bidart Campos, G. J. (1967). El Derecho Constitucional del Poder (Tomo II). Ediar.

Bidart Campos, G. J. (2002/2004). Tratado Elemental de Derecho Constitucional Argentino (Tomo II-B). Ediar.

De Vedia, A. (1907). Constitución Argentina. Coni Hnos.

Diegues, J. (2015). El nombramiento en comisión de jueces de la Corte Suprema. La Ley. Suplemento Especial. Designación de Jueces de la Corte Suprema. LXXIX(236).

Ekmekdjian, M. A. (2016). Tratado de Derecho Constitucional (2 ${ }^{\mathrm{a}}$ ed., Tomo V). Abeledo Perrot. González Calderón, J. A. (1916). Derecho Constitucional (Tomo II). Lajouanne.

Linares Quintana, S. V. (1987). Tratado de la Ciencia del Derecho Constitucional Argentino y Comparado (Tomo 9). Plus Ultra.

Manili, P. L. (2017). Evolución de la Jurisprudencia de la Corte Suprema (2a ed.). Astrea.

Sola, J. V. (2015). La designación de jueces en comisión. La Ley. Suplemento Especial. Designación de Jueces de la Corte Suprema, LXXIX(236). 
